\title{
Prediction of the Mechanical Power in Wind Turbine Powered Car UsingVelocity Analysis
}

\author{
Youssef Kassem, Hüseyin Çamur, Abdelrahman Alghazali* \\ Department of Mechanical Engineering, Near East University, Nicosia, Cyprus
}

Email address:

abdelrahman.alghazali@neu.edu.tr (A. Alghazali)

${ }^{*}$ Corresponding author

\section{To cite this article:}

Youssef Kassem, Hüseyin Çamur, Abdelrahman Alghazali. Prediction of the Mechanical Power in Wind Turbine Powered Car Using Velocity Analysis. American Journal of Science, Engineering and Technology. Vol. 3, No. 1, 2018, pp. 10-20.

doi: $10.11648 /$ j.ajset.20180301.12

Received: October 6, 2017; Accepted: February 3, 2018; Published: March 2, 2018

\begin{abstract}
Savonius is a drag type vertical axis wind turbine. Savonius wind turbines have a low cut-in speed and can operate at low wind speed. It is suitable for small scale power generation, such as individual domestic installations. In this paper, investigation into the relationship between the type of Savonius rotor, the torque and the mechanical power generated was carried out. Also an illustration on how the type of rotor plays an important role in the prediction of mechanical power of wind turbine powered car. The main purpose of this paper is to predict and investigate the aerodynamic effects by means of velocity analysis on the performance of a wind turbine powered car by converting the wind energy to mechanical energy to overcome load applied on the rotating main shaft. The predicted result based on theoretical analysis is compared with experimental results obtained from literature. Prediction of the torque was done at a wind speed of $4 \mathrm{~m} / \mathrm{s}$, and an angular velocity of 130 RPM according to meteorological statistics in Northern Cyprus.
\end{abstract}

Keywords: Mechanical Power, Torque, Savonius Rotor, Velocity Analysis, Wind Car

\section{Introduction}

An increase in the use of wind energy in the past decade[1] has inspired extensive researches on the wind turbine technology, with more focus on Savonius wind rotor. It was developed 1925 by Sigurd Savonius, a Finnish engineer as a vertical axis wind rotor [2]. The Savonius wind rotor is one of the simplest and cheapest vertical axis wind turbines. It has good starting characteristics with initial high torque, relatively low operating speeds and ability to capture wind and operate from any direction [3]. It has many applications, including domestic and small scale power generation. The major setback of this rotor is its low aerodynamic efficiency.

Much work has been done to study the aerodynamic characteristics and effects of geometric design parameters in Savonius wind turbines.

Bhaskar and Gaurav [4] made numerical analysis using (computational fluid dynamic (CFD) software ANSYSFLUENT) on a two-Bladed Savonius Rotor, a study on drag and torque coefficient curves at different rotor blade angles at each $10^{\circ}$ interval was carried out. These curves show that the drag and torque coefficients reached its maximumat $0^{\circ}$ and $30^{\circ}$ rotor blade angles respectively.

Mohammed [5] carried out an experimental study using subsonic wind tunnel under low wind speed, and compared the performance of two and three blades of Savonius wind turbine rotor. The result showed that an increase in the number of blades increases the drag surfaces against the wind-air flow and causes it to increase the reverse torque. This effect leads to a decrease in the net torque working on the blades of a Savonius wind turbine.

Konrad et al. [6] Investigated numerically, the running performance of Bach-type and Elliptical designs Savonius wind turbine rotor, using ANSYS CFX.The running performance of the Savonius rotor, such as the torque coefficient, is obtained for various tip speed ratios. It was discovered that the Bach-type has a maximum torque and power coefficient whilst the Elliptical Savonius turbine has better performance in terms of power characteristics.

Kawamura et al. [7] investigated the running performance of the rotor, using a domain decomposition method. A two connected computational domains containing rotating rotor and fixed wall respectively, were done; both domains have 
common overlapping regions. The running performance of the Savonius rotor; such as the torque coefficient, were obtained for various tip speed ratios. The effects of the walls on the running performance were also investigated. It was found that the power coefficient was raised significantly.

Sargolzaei [8] used artificial neural networks (ANNs) to predict the power factor and torque for over seven prototype vertical Savonius rotor turbines based on experimental data. According to the simulation and experimental results, they provided reasonable computations for the maximum power of rotors and maximizing the efficiency of Savonius wind turbines. Also, increasing Reynolds number led to an increase in power ratio and torque.

Gad et al.[9] used the commercial software, Fluent, with four different turbulence models to modify Savonius wind rotor. The results showed that modifying the blades of the rotor causes an increase of the performance of the rotor.

Kamoji et al. [10] studied experimentally the torque of a conventional Savonius rotor for variable overlaps ratio, blade edge condition and change in Reynolds number. The results indicated that the decreasing static torque coefficient results to increase in the overlap ratio. Also the power coefficient is dependent of Reynolds number, whereas the static torque coefficient is independent of Reynolds number.

Saha et al. [11] studied experimentally the performance of single, two and three -stage of the Savonius rotor system and the effect of number of stages, number of blades and geometry of the blade on the Savonius rotor system performance at different wind speed. The study concluded that twisted geometry blade profile performs better than semicircular blade geometry with a better power coefficient in a two-stage Savonius rotor when compared to the singleand three-stage rotors.

Keum el at. [12] experimentally studied the effect of end plates with various shapes andsize on the aerodynamic performance of helical Savonius wind turbine with twist angle and two semi-circular buckets. The results showed the power coefficient increased linearly in proportion to the area of the end plate.

Bhaumik et al. [13]measured experimentally the power coefficient of a two-bladed helical Savonius wind rotor at the exit of a centrifugal blower for five different overlap ratios.

Kamoji et al. [14] evaluated the power and static torque coefficient of a helical Savonius rotor in an open jet wind tunnel test under various design and operating conditions.

Wind powered car has also been constructed using different type of wind turbine at different aerodynamic characteristics.

Ventomobile, a three-wheeled "car" which features a 2meter diameter two-bladed rotor mounted on top was built by team InVentus[15-17]

Wind powered car, Faster than the Wind, was constructed in New Jerusalem in Tracy, Californiaby Cavallaro [18]

Along the dry plains of Ivanpah Lake in Nevada, Windpowered vehicle or Wind-powered Green bird reached speeds of $126.1 \mathrm{mph}(202.9 \mathrm{~km} / \mathrm{h})$. [19]

"Wind Explorer", a wind-powered car, which was created by two German inventors, recharges the battery through a wind turbine carried in the car. To test the vehicle, the duo recently completed a 3,100-mile trek across Australia. [20, 21]

Following these studies, the theoretical study was applied to predict the mechanical power in wind turbine powered car. This paper aims at studying the effect of the shape of the rotor of Savonius vertical axis wind turbine on the performance of wind turbine powered car through theoretical study using velocity analysis.

\section{Method}

\subsection{Principles of Savonius Rotor Wind Turbine}

A Savonius rotor is a drag-type turbine [22, 23].In the simplest form, a Savonius rotor consists of two half-cylinder sections fixed to a half in the form that their cross section makes a letter " $\mathrm{S}$ " as shown in Figure 1. In operation, one blade captures the wind while the other moves against the wind, thus opposing the wind. The net torque to rotate the turbine is the torque from the blade capturing the wind energy minus the resistive torque that the other blade receives against moving. This is the case for all the drag type turbines. One can add more half cylinders on the shaft in order to increase the capacity of wind capture. It will also increase the length of the cylindrical sections, provided all the sections are aligned. Alternatively a second set can be installed at $90^{\circ}$ from the first half cylinders. This adds to uniformity of rotational torque on the half of the shaft since with only two half cylinders, the absorbed power pulsates making it uniform as the rotor turns.

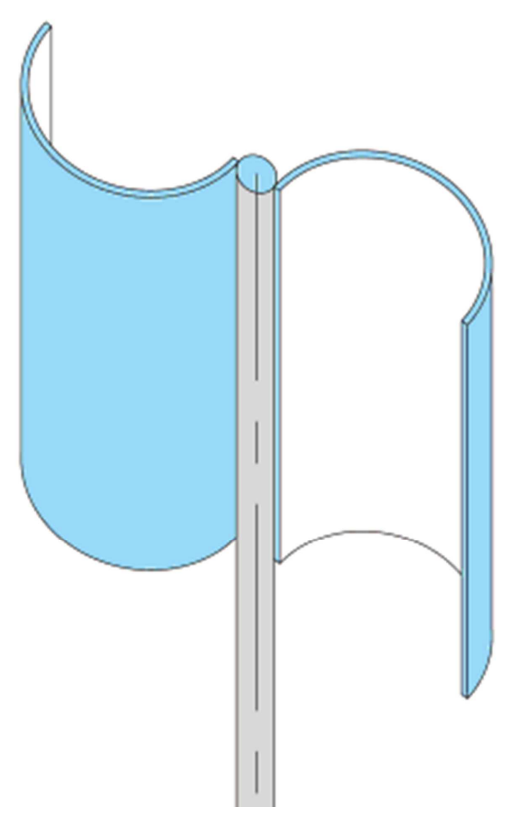

Figure 1. Construction of Savonius rotor.

A Savonius rotor has about half of the power capture capability of the other (lift-based) turbines; its power coefficient at optimum performance is about half of the magnitude that can be achieved by a propeller turbine. In order to increase the power capture capability of a Savonius 
turbine, certain modifications to the basic design have been proposed. Firstly, is to create a gap in the structure where the two halves cylinders are joined. This allows the air to pass through this gap from the segment capturing wind to the segment opposing wind, as depicted in Figure 2. The advantage of the twofold: wind is not trapped in the capturing blade and has a more steady flow, and the opposing blade has an extra force to help it push the air.[23]
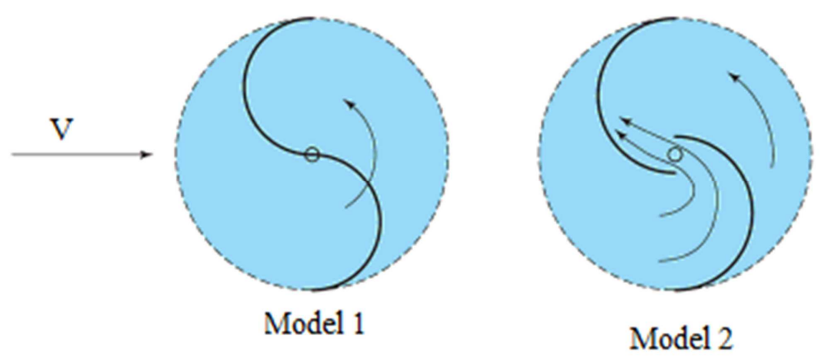

Figure 2. Alternative designs for Savonius rotor

\subsection{Savonius Wind Turbine Theory}

The Savonius wind turbine is one of simplest turbines. Figure 3 shows the schematic drawing of drag forces exert on the blades of the conventional Savonius rotor. From the wind direction, the concave part catches the wind current and forces the blade to rotate about its central vertical shaft. It will experience more drag forces. However, the convex part will experience less drag force when the wind hits the blade and causes the air wind to be deflected a way around it. Hence, the differential drag causes the rotor to rotate and leads the Savonius turbine to spin. [20]
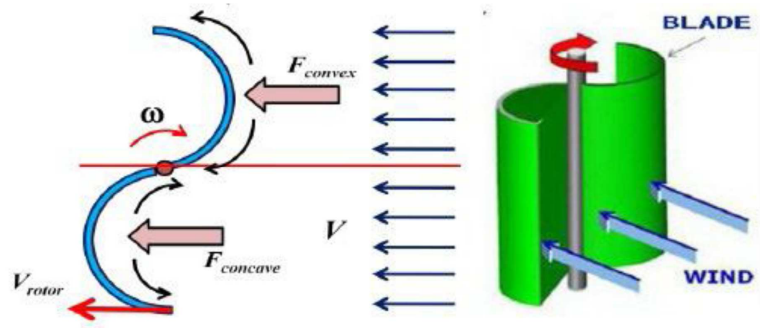

Figure 3. Two blades Savonius wind turbine with the drag forces [24].

The performance of Savonius wind turbine can be expressed in the form of torque coefficient $\left(\mathrm{C}_{t}\right)$ and the coefficient of power $\left(\mathrm{C}_{\mathrm{p}}\right)$ in comparison with the tip speed ratio or TSR is a parameter related to rated wind speed and rotor diameter. As the ratio between the speed of tip blade and wind speed through the blade, TSR can be determined as [25]

$$
T S R=\lambda=\frac{V_{\text {rotor }}}{V}=\frac{\omega d}{V}
$$

where

$\mathrm{V}_{\text {rotor }}$ : tip speed of the peripheral velocity of the rotor $(\mathrm{m} / \mathrm{s})$,

$\omega$ : angular velocity of therotor $(1 / \mathrm{s})$,

$\mathrm{d}$ : diameter of a half cylinder of rotor $(\mathrm{m})$, and

$\mathrm{V}$ : wind speed $(\mathrm{m} / \mathrm{s})$.

The coefficient of torque is defined as the ratio between the actual torque develop by the rotor $(\mathrm{T})$ and the theoretical torque available in the wind $\left(\mathrm{T}_{\mathrm{w}}\right)$ as,

$$
C_{t}=\frac{T}{T_{w}}=\frac{4 T}{\rho A_{s} d V^{2}}
$$

where

$$
\rho: \text { air density }\left(\mathrm{kg} / \mathrm{m}^{3}\right)
$$

T: the torque (N.m) and

$\mathrm{A}_{\mathrm{s}}$ : the swept area of blades $=$ the rotor height $\mathrm{x}$ the rotor diameter $\left(\mathrm{m}^{2}\right)$.

The coefficient of power of a wind turbine $\left(\mathrm{C}_{\mathrm{p}}\right)$ is the ratio between the maximum power obtained from the wind $\left(\mathrm{P}_{t}\right)$ and the total power available from the wind $\left(\mathrm{P}_{\mathrm{a}}\right)$ as,

$$
C_{p}=\frac{P_{t}}{P_{a}}=\frac{P_{t}}{\frac{1}{2} \rho A V^{3}}
$$

Where the maximum power of a wind turbine is determined as [26],

$$
P_{t}=T \omega[W a t t]
$$

\subsection{Gearbox (Bevel Gears)}

Bevel gears have a conical form and can be used to transmit rotational power through shafts at right angle to each other [27]. Bevel gears are among the key elements in a power transmitting system with intersecting axes. [28]

In the past, researches in this area were limited, the gears were considered as having a high efficiency, with a reduced frictional loss. But in the current conditions of the global economy development, the means of obtaining energy from renewable sources and energy saving has become important issues thus researches are being geared towards.

Gear efficiency varies according to its type and application. The approximate efficiency range of the straight bevel gear is $97 \%-99 \%$ [29].

The basic shape of a bevel gear tooth is almost the same as that of the spur gear. The tooth tapers off as it approaches the apex. The contour of the tooth also varies along its entire length. The angle between the shafts will depend on the conditions of the drive. It is usually $90^{\circ}$, but can have other angles also. The configurations of the straight sided bevel gears have been shown in Figure 4. [30] 


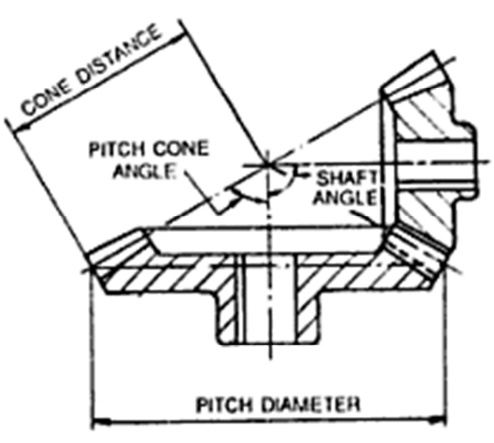

(a)

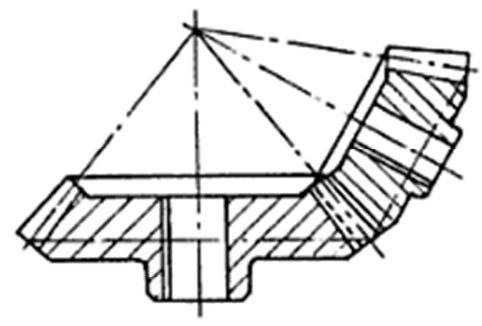

(c)
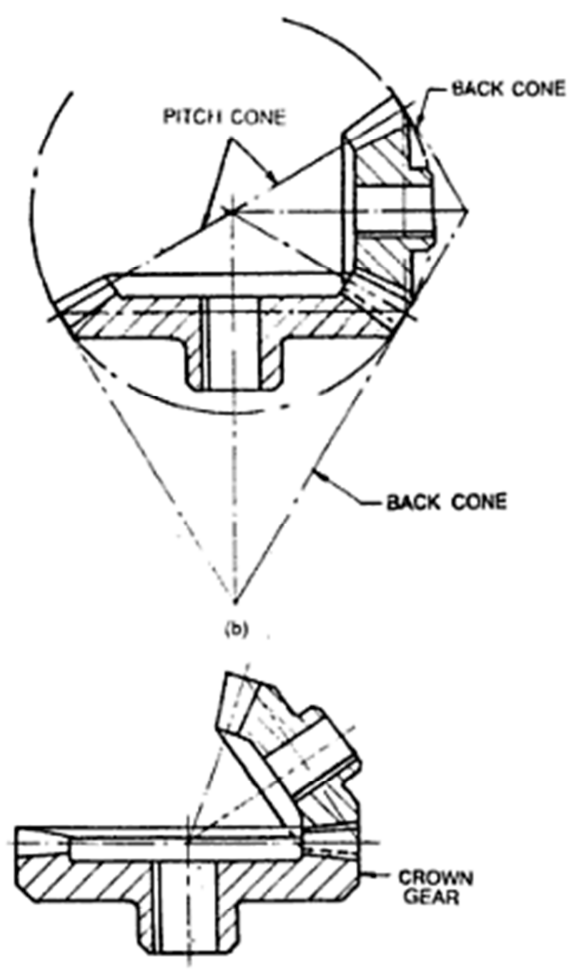

(c)

Figure 4. The configurations of the straight sided bevel gears.

\subsection{Energy Losses in a Vehicle}

a. Aerodynamic Drag Loss

Aerodynamic drag comprises of normal (pressure) and tangential (friction) forces acting on a vehicle shape as it moves through the air. The size of the drag force depends on the density of the air, the vehicle size, shape and square of the speed. Vehicle design can focus on reducing aerodynamic losses by reducing a vehicle's drag coefficient and frontal area which is primarily determined by a vehicle's shape. [31]

A vehicle expends energy to move air out of the way translating to less energy at lower speeds and progressing more as speed increases. Drag is directly related to the vehicle's shape [32]. The energy lost due to aerodynamic drag is about $2.6 \%$ of total energy $[32,31]$.

b. Rolling Resistance Losses

Rolling resistance acts in parallel to vehicle motion and along the road surface. It is dependent on the weight of the vehicle and the coefficient of rolling resistance of the tire. The tire rolling resistance is a function of the number of factors, including: vehicle loading; inflation pressure; wheel diameter; speed rating and the road conditions for which the tire is designed. The rolling resistance coefficient of modern tires has decreased over the last 30 years by approximately $10 \%$ to a medium value of 0.0099 . [31]

Rolling resistance is a measure of the force necessary to move the tire forward and is directly proportional to the weight of the load supported by the tire. A variety of new technologies can be used to reduce rolling resistance, including improved tire tread and shoulder designs and materials used in the tire belt and traction surfaces. [32]
When moving at a near constant speed, the rolling friction coefficient can be considered as a constant. About $4.2 \%$ of the total energy is lost because of the rolling resistance. [28,33]

c. Drivetrain Losses

More than $5 \%$ of energy is lost in the transmission and other parts of the Drivetrain. Two main causes of transmission losses include the sliding contact of the gear and oil fling and windage. The technologies, such as automated manual transmission and a continuously variable transmission, are developed to reduce these losses. [33]

d. Kinetic Energy Losses

Every time a vehicle accelerates, kinetic energy is transferred to the vehicle. This energy is largely lost as heat in the brakes as the vehicle slows down. The kinetic energy is dependent on the mass of the vehicle and square of the speed of the vehicle. Mass is the largest contributor to the intermittent power requirements of a vehicle and is the most important factor in determining the power rating of power components and the amount of energy a vehicle must store on board. Light weight strategies often focus on the material substitution and vehicle component redesign. The vehicle subsystem which is affected by light weights are the suspension, tires and wheel, transmission, structure, steering and brakes. Moreover, a lighter vehicle requires less power to achieve a given acceleration.[31]

\section{Results}

a. Wind car body

The wind car model was designed using Solidwork 2013. 
Figure 5 shows the processes of converting the wind energy into useful energy which is described as follows;

a) Extracting kinetic energy at the rotor axis, and

b) Conversion of such kinetic energy into mechanical energy

Figure 6 shows a schematic three dimensional view of the wind turbine powered car. The model has a different Savonius rotor type. Moreover, the Savonius rotor is directly connected to the wheels by using various kinds of links. The straight bevel gear is used to convert the wind energy to mechanical energy to overcome the load exercised on the main shaft under low speed. The torque and mechanical power are measured at a wind speed $4 \mathrm{~m} / \mathrm{s}$. The dimensions of wind turbine powered car models, as mention in Figure 2, are shown in Table 1.

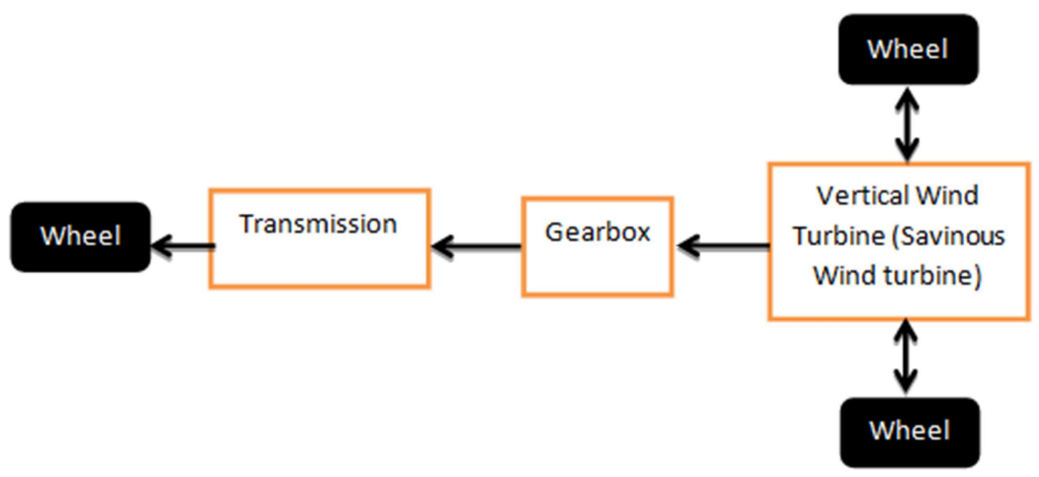

Figure 5. Conversion of wind energy to mechanical power through a wind turbine.

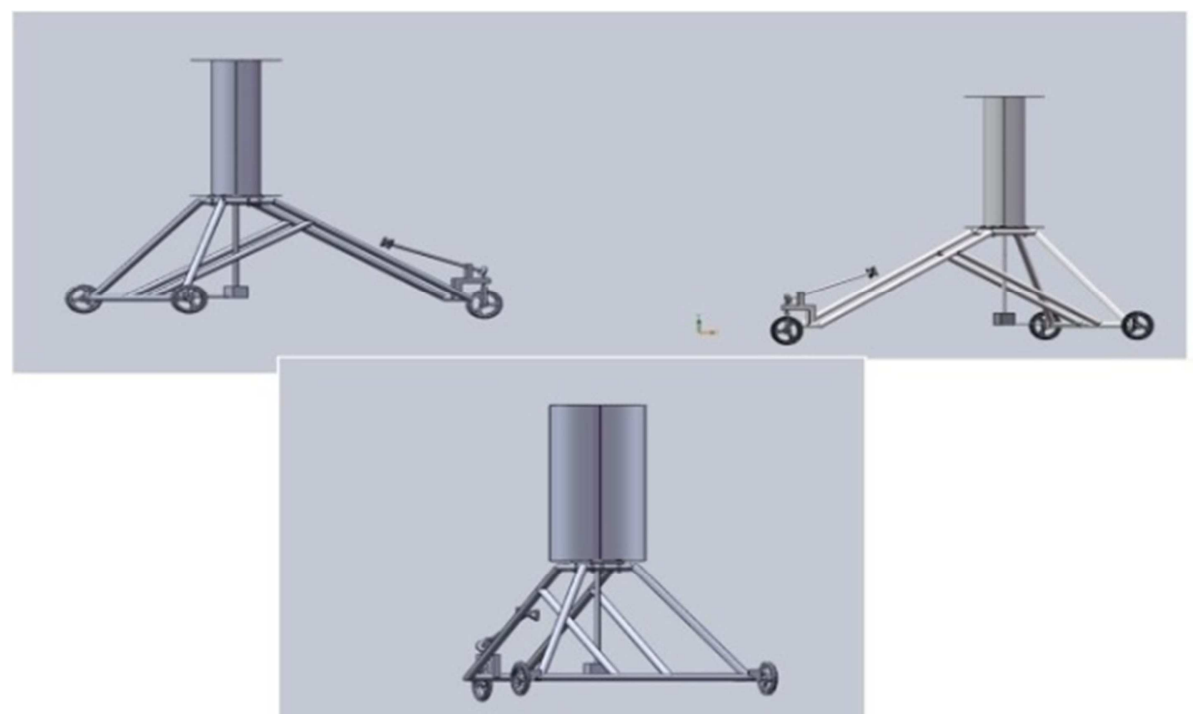

Figure 6. Three dimensional views of wind turbine powered car.

Table 1. Dimensions of the models of the vertical axis wind turbine car.

\begin{tabular}{|c|c|c|c|c|c|}
\hline \multicolumn{6}{|c|}{ Dimensions of models } \\
\hline Car Body & & Savonius wind turbine & & & \\
\hline Height $[\mathrm{m}]$ & 1.2 & Model 1 & & Model 2 & \\
\hline Width [m] & 2 & Height $(\mathrm{H})[\mathrm{m}]$ & 2 & Height $(\mathrm{H})[\mathrm{m}]$ & 2 \\
\hline Length [m] & 3 & Rotor Diameter (D) [m] & 1 & Rotor Diameter [m] & 1 \\
\hline- & & Semi-cylinder diameter $(\mathrm{d})[\mathrm{m}]$ & 0.5 & Semi-cylinder diameter $(\mathrm{d})[\mathrm{m}]$ & 0.5 \\
\hline- & & Gap Length (e) [m] & 0.0 & Gap Length (e) [m] & 0.1 \\
\hline
\end{tabular}

b. Velocity analysis of Savonius wind turbine rotor

Figure 7 shows the direction of the wind speed $\left(\mathrm{V}_{\text {wind }}\right)$, the direction of the speed of the blades $\left(\mathrm{V}_{\text {rotor }}\right)$, the position of the blades with angle $\theta$, and the direction of rotation of the blades. Also, Figure 8 shows the velocity components of the wind speed during the rotation of the rotor. The wind speed is broken into two components: $\mathrm{X}$, and $\mathrm{Y}$ as shown in Figure 8 . Vertical flows were not considered in this research, and could be a topic for future exploration. Assuming that the axis of the Savinous wind turbine rotor is the upward-pointing $\mathrm{Y}$ axis, the flow experienced in the $\mathrm{X}$-direction is the sum of the free-stream flow in the $\mathrm{X}$-direction, and the $\mathrm{X}$-aspect of rotational velocity (see Figure 9).

Figure 10 shows the variations of velocity magnitude at different rotor blade angles for every $30^{\circ}$ change in the rotor blade angle. It is observed that the velocity magnitude of 
model 1near the advancing rotor blade tip attains its maximum at a $0^{\circ}$ rotor blade angle. This velocity, then decreases until a $90^{\circ}$ rotor angle and then starts to increase to reach the peak point at $220^{\circ}$ and $240^{\circ}$.

Whereas, it is observed that the velocity magnitude of model
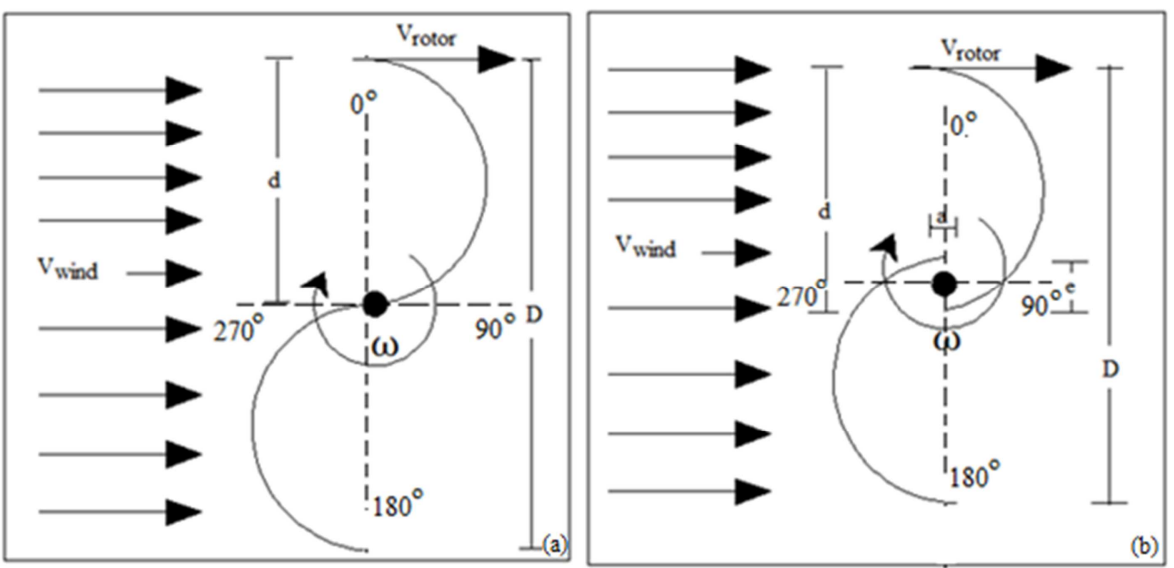

Figure 7. Schematic diagram of a different two bladed Savonius rotor; (a): model 1,(b): model 2

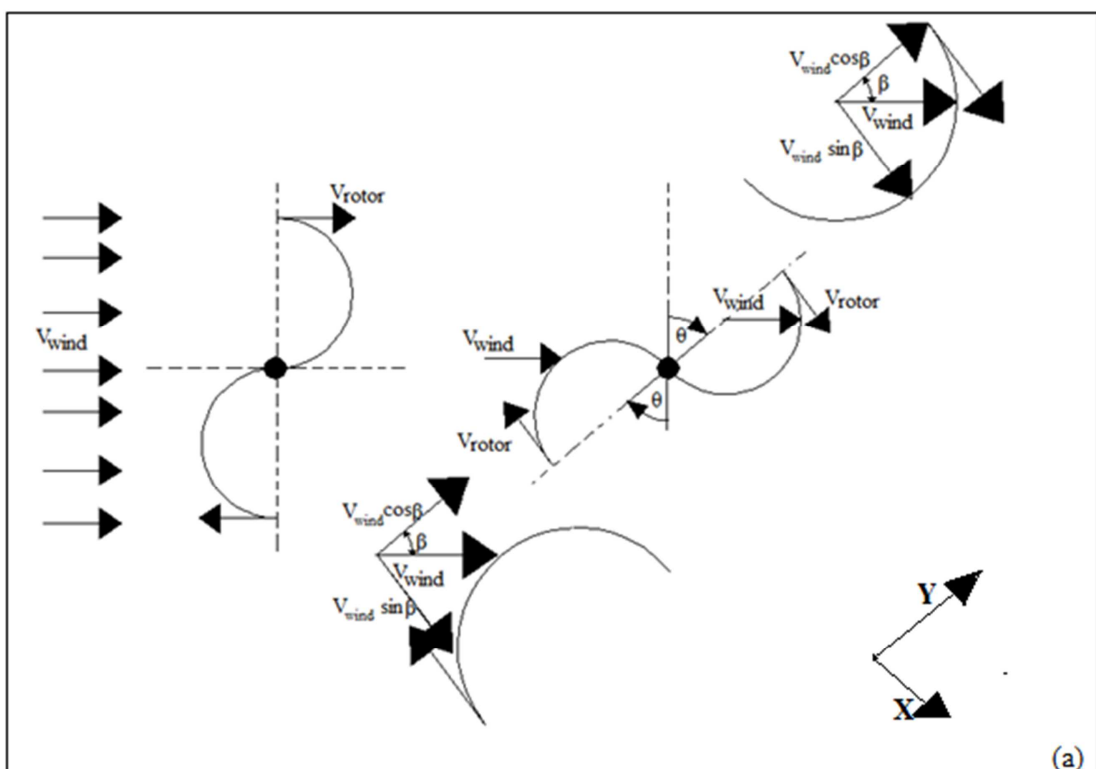

(a)
2 is increased to attain its maximum at $30^{\circ}$ rotor blade angle. Then velocity starts to diminish to a $90^{\circ}$ rotor blade angle and then again starts increasing till reach the maximum velocity at $180^{\circ}$. Then velocity starts to diminish till become nearly zero.

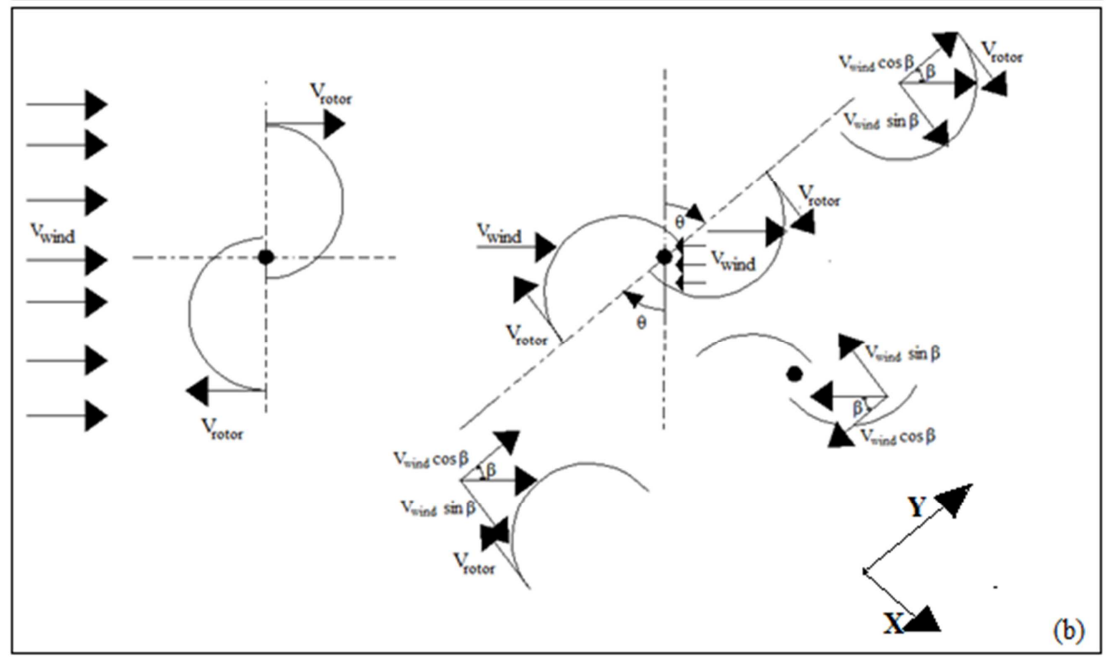

Figure 8. Vector components of the wind speed at Savonius rotor; (a): model 1,(b): model 2 

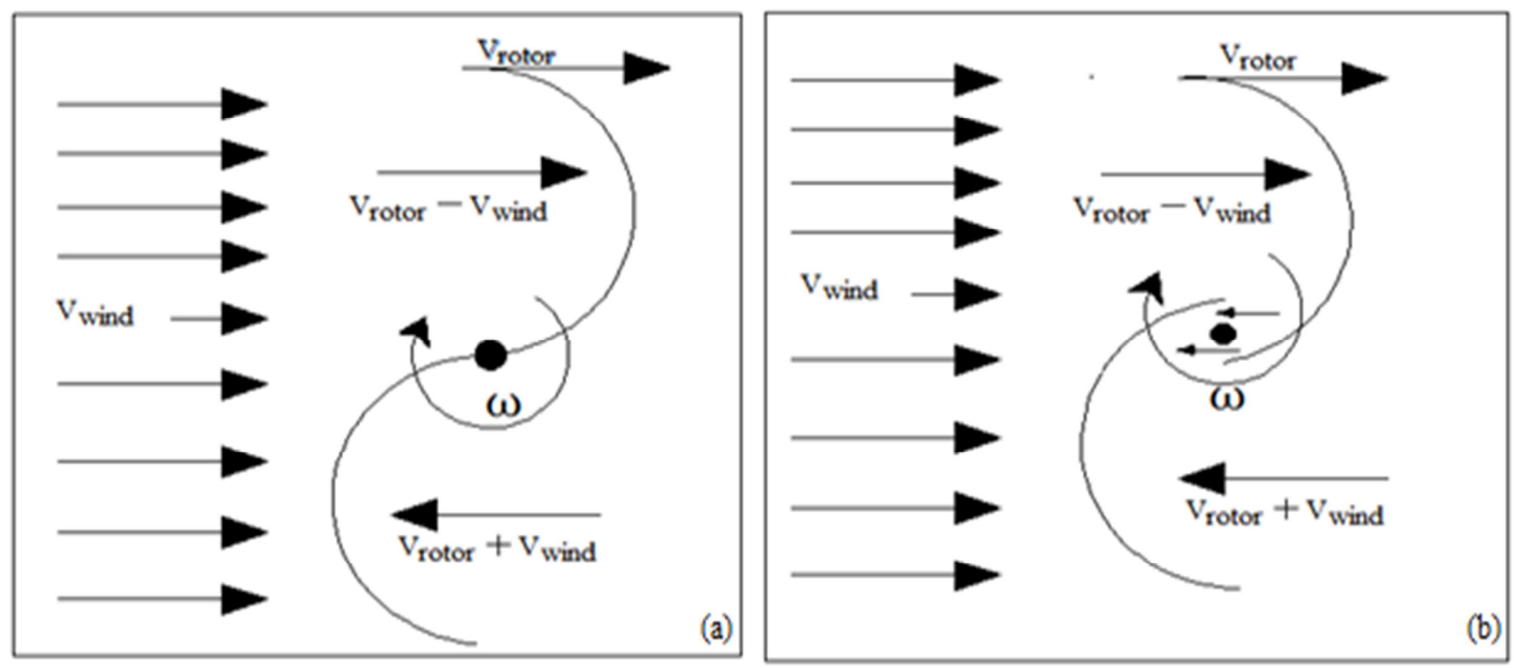

Figure 9. Scheme of a Savonius rotor showing the velocity of the rotor and wind speed; (a): model 1, (b): model 2.

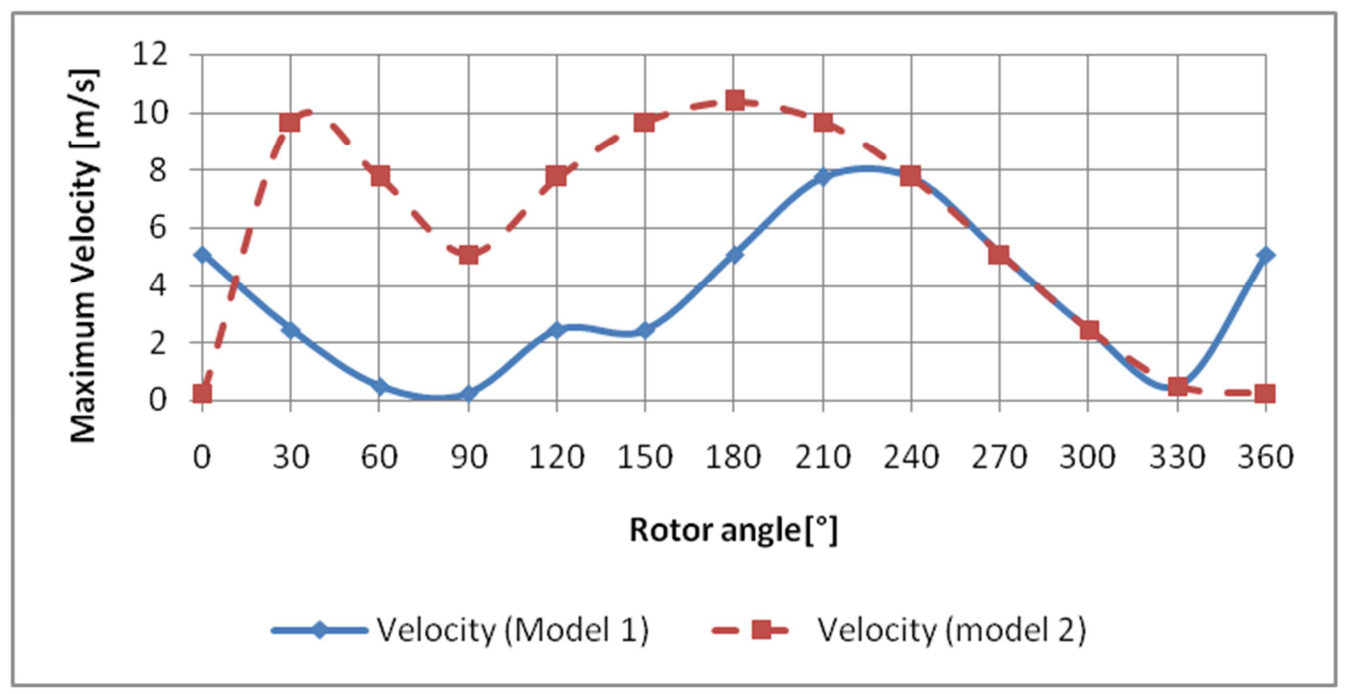

Figure 10. Comparison of maximum velocity developed at different rotor angles.

c. Comparison of Theoretical and Experimental ${ }^{1}$ Torque of Savinous wind turbine rotor (Model 1)

Before applying the theoretical study in wind turbine powered car, a comparative study has been done between the theoretical study with ${ }^{5}$ using the same dimension of Savonius wind turbine, wind speed and angular rotation. Figure 11 and Table 2 shows the comparison between experimental and theoretical predictions data torque of the Savinous wind turbine rotor (model 1). Also, the percentage of error between them is shown in Table 2. As can be seen, the percentage of error between the theoretical predictions and experimental data at $0^{\circ}, 90^{\circ}, 150^{\circ}, 180^{\circ}, 270^{\circ}, 330^{\circ}$, and $360^{\circ}$ is zero percent. Whereas, at $30^{\circ}, 60^{\circ}, 120^{\circ}, 210^{\circ}, 240^{\circ}$, and $300^{\circ}$ the percentage error between the experimental and theoretical data is in the range between 3 and 24 percent.
Table 2. Percentage Error between the experimental and prediction data with rotor angle of Savonius wind turbine rotor (Model 1).

\begin{tabular}{llll}
\hline $\begin{array}{l}\text { Rotor } \\
\text { angle }\left[{ }^{\circ} \text { ] }\right.\end{array}$ & $\begin{array}{l}\text { Torque [N.m] } \\
\text { Experimental }\end{array}$ & $\begin{array}{l}\text { Theoretical } \\
\text { data }\end{array}$ & $\begin{array}{l}\text { Percentage } \\
\text { Error [\%] }\end{array}$ \\
\hline 0 & 0.039 & 0.039 & 0 \\
30 & 0.058 & 0.056 & 3.4 \\
60 & 0.038 & 0.047 & 23.6 \\
90 & 0.02 & 0.02 & 0 \\
120 & 0.014 & 0.013 & 7.1 \\
150 & 0.009 & 0.009 & 0 \\
180 & 0.039 & 0.039 & 0 \\
210 & 0.058 & 0.056 & 3.4 \\
240 & 0.038 & 0.047 & 23.6 \\
270 & 0.02 & 0.02 & 0 \\
300 & 0.014 & 0.013 & 7.1 \\
330 & 0.009 & 0.009 & 0 \\
360 & 0.039 & 0.039 & 0 \\
\hline
\end{tabular}

1 Experimental data of Savonius wind turbine rotor which was done by experiments are taken from reference ${ }^{5}$. 


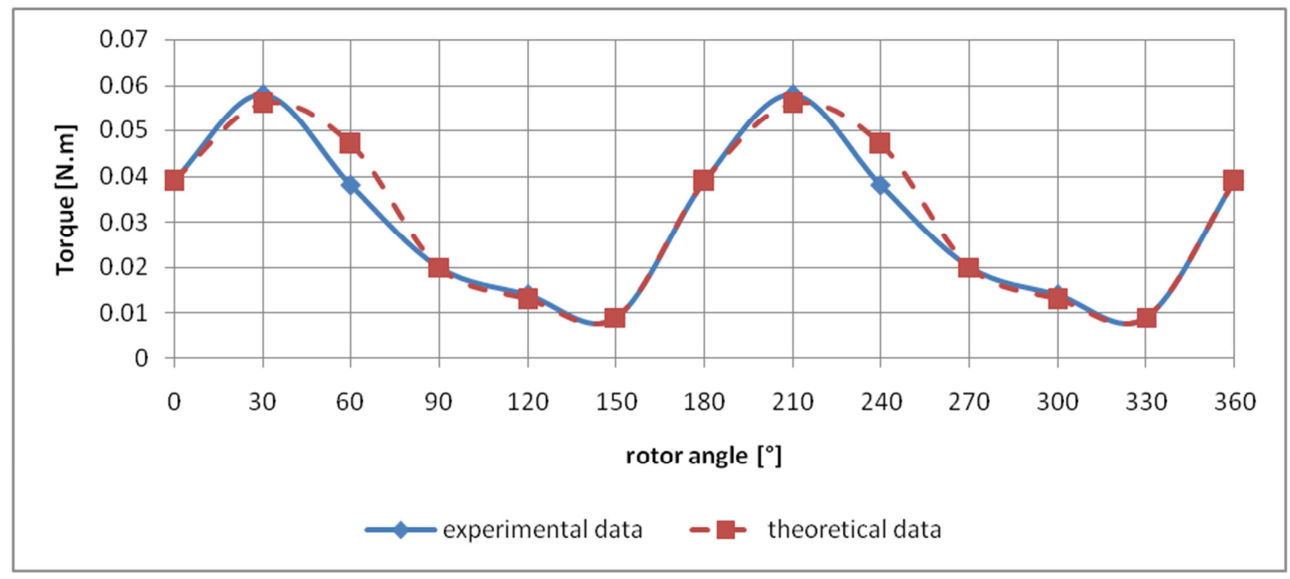

Figure 11. Theoretical predictions and experimental torque of the Savinous wind turbine rotor (model 1).

d. Torque and Mechanical Power of Wind Turbine Powered car

Most of the energy is lost in Drivetrain operations and overcoming resistances such as aerodynamic drag and rolling resistance. Reducing the overall vehicle energy losses is necessary and meaningful. The percentage of various energy losses within a vehicle, mentioned in section 5 are shown in Table 3.

The theoretical procedure for calculating the torque and mechanical power of wind turbine powered car is represented in Figure 12.

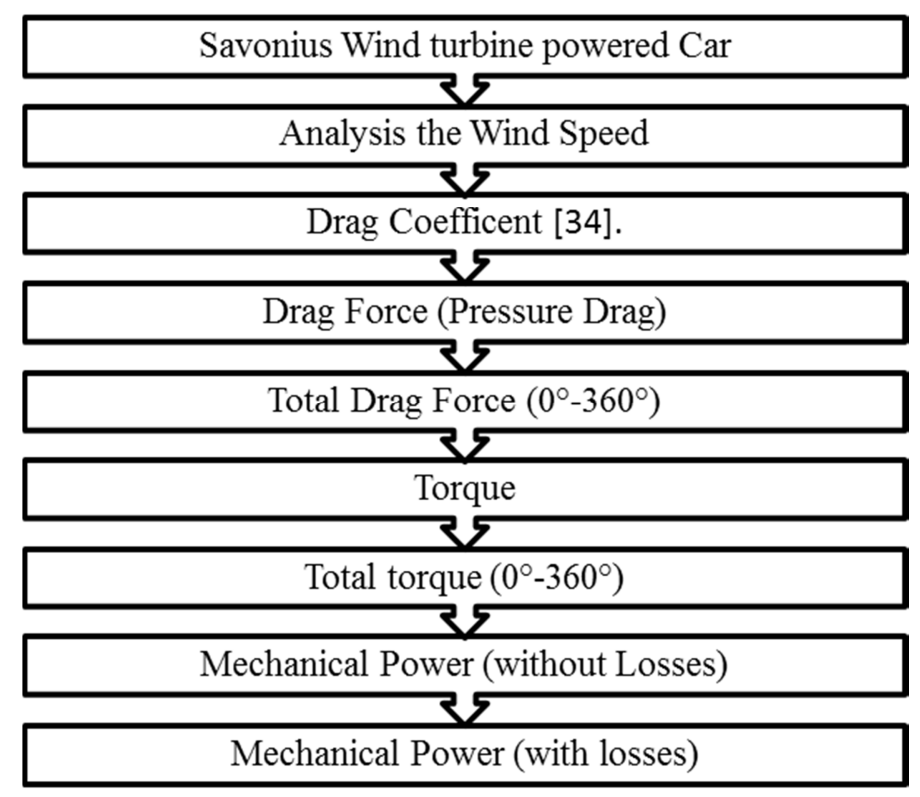

Figure 12. Procedure for calculating the torque and mechanical power of wind turbine powered car.

Table 3. Percentage of vehicle energy losses.

\begin{tabular}{ll}
\hline Losses in a Vehicle & \\
\hline Aerodynamic Drag Loss [\%] & 2.6 \\
Rolling Resistance Losses [\%] & 4.2 \\
Drivetrain Losses [\%] & 5.62 \\
\hline
\end{tabular}

It is observed from Figure 12 and 13 that the mechanical power of two models varies with the rotor angle for a wind speed of $4 \mathrm{~m} / \mathrm{s}$. Also, the mechanical power and torque were calculated at every $30^{\circ}$ as shown in Table 4 and Figure 12 and 13. It appears the mechanical power that can be produced during each revolution is an oscillatory power.

2Percentage of Drivetrain Losses in conventional vehicle as in [33]
Figure 12 shows the mechanical power of the model 1 varies with increasing angle of rotation, it starts to increase from $\left(0^{\circ}\right.$ to $\left.30^{\circ}\right)$ and reaches its maximum value of $328.35 \mathrm{~W}$ and it thendecreases from $\left(30^{\circ}\right.$ to $\left.150^{\circ}\right)$ to reach its lowest value of $131.64 \mathrm{~W}$. It is noticeable that Mechanical power values are yielding the symmetry for flow angles higher than $\left(180^{\circ}\right.$ to $\left.360^{\circ}\right)$. Figure 13 shows the variation of the mechanical power with rotor angle for model 2. The mechanical power starts to increase from $0^{\circ}$ and attains its maximum value at a $30^{\circ}$ rotor angle, then it drops to a minimum at a $90^{\circ}$ rotor blade angle, then again starts increasing. Table 4 and Figure 12 and 13 also confirms the fact that Savonius rotors are self-starting i.e. they start to 
rotate irrespective of the wind flow direction as the torque value was found to be positive for each rotor blade angle.

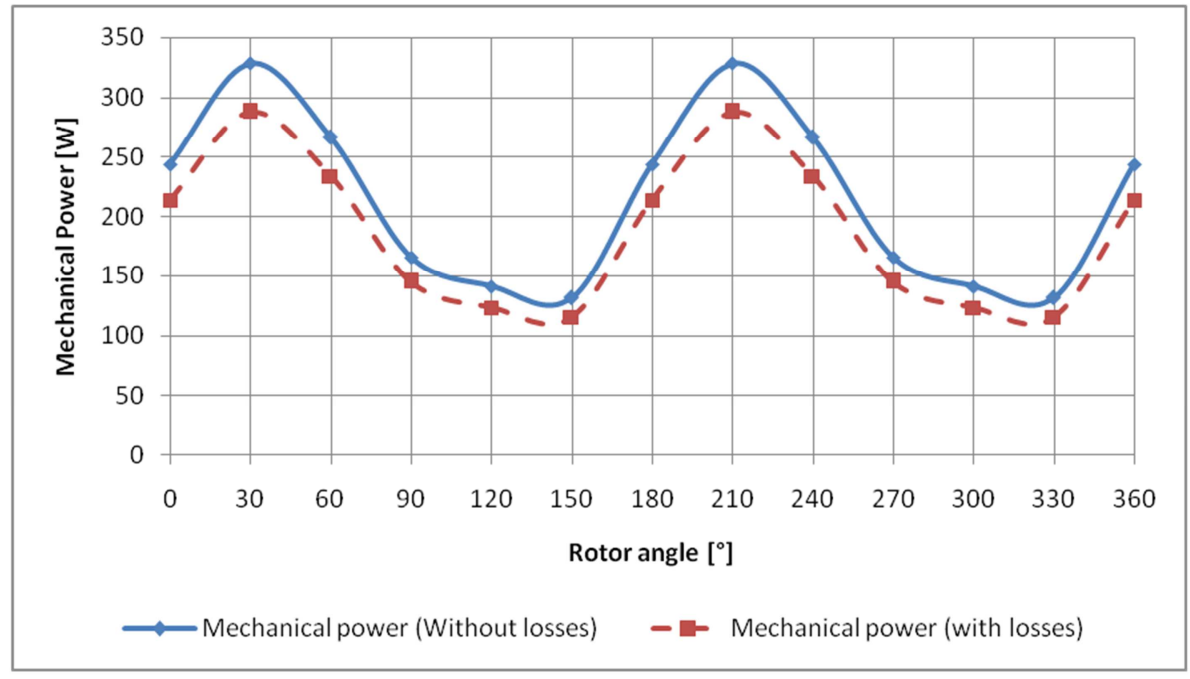

Figure 13. Comparison of the mechanical power of model 1 at different rotor angles.

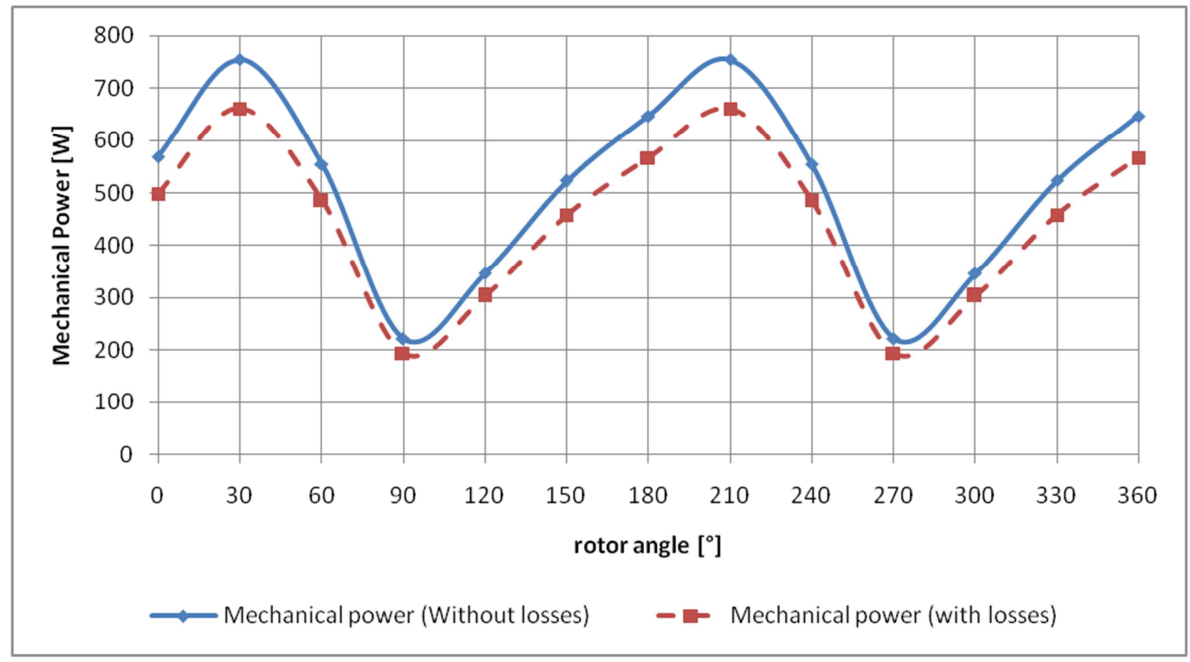

Figure 14. Comparison of the mechanical power of model 2 at different rotor angles.

Table 4.Theoretical results of torque and mechanical power for two models of wind turbine powered car.

\begin{tabular}{|c|c|c|c|c|c|c|c|}
\hline \multirow{2}{*}{$\begin{array}{l}\text { Model 1 } \\
\begin{array}{l}\text { Rotor } \\
\text { angle }\left[{ }^{\circ}{ }^{\circ}\right]\end{array}\end{array}$} & \multirow[b]{2}{*}{$\begin{array}{l}\text { Torque } \\
\text { [N.m] }\end{array}$} & \multirow[b]{2}{*}{$\begin{array}{l}\text { Mechanical } \\
\text { Power (Without } \\
\text { Losses) [W] }\end{array}$} & \multirow[b]{2}{*}{$\begin{array}{l}\text { Mechanical } \\
\text { Power (With } \\
\text { Losses) [W] }\end{array}$} & \multicolumn{2}{|l|}{ Model 2} & \multirow[b]{2}{*}{$\begin{array}{l}\text { Mechanical } \\
\text { Power (Without } \\
\text { Losses) [W] }\end{array}$} & \multirow[b]{2}{*}{$\begin{array}{l}\text { Mechanical } \\
\text { Power (With } \\
\text { Losses) [W] }\end{array}$} \\
\hline & & & & Rotor angle $\left[^{\circ}\right]$ & Torque [N.m] & & \\
\hline 0 & 17.89 & 243.54 & 213.34 & 0 & 41.73 & 568.22 & 497.76 \\
\hline 30 & 24.12 & 328.35 & 287.64 & 30 & 55.41 & 754.35 & 660.81 \\
\hline 60 & 19.59 & 266.68 & 233.62 & 60 & 40.74 & 554.68 & 485.904 \\
\hline 90 & 12.16 & 165.54 & 145.01 & 90 & 16.28 & 221.71 & 194.22 \\
\hline 120 & 10.34 & 140.76 & 123.3 & 120 & 25.45 & 346.46 & 303.50 \\
\hline 150 & 9.67 & 131.64 & 115.31 & 150 & 38.42 & 523.15 & 458.28 \\
\hline 180 & 17.89 & 243.54 & 213.34 & 180 & 47.52 & 646.64 & 566.46 \\
\hline 210 & 24.12 & 328.359 & 287.64 & 210 & 55.40 & 754.30 & 660.76 \\
\hline 240 & 19.59 & 266.689 & 233.62 & 240 & 40.74 & 554.67 & 485.89 \\
\hline 270 & 12.16 & 165.54 & 145.01 & 270 & 16.28 & 221.73 & 194.23 \\
\hline 300 & 10.34 & 140.76 & 123.3 & 300 & 25.45 & 346.46 & 303.50 \\
\hline 330 & 9.67 & 131.64 & 115.31 & 330 & 38.43 & 523.17 & 458.30 \\
\hline 360 & 17.89 & 243.54 & 213.34 & 360 & 47.52 & 646.64 & 566.46 \\
\hline
\end{tabular}




\section{Conclusions and Future Works}

In this study, the authors theoretically analyzed the geometry of wind turbine powered car using different types Savonius wind turbine rotor. The main outcomes of these analyses are, the drag force of the model 2 is higher than the other model and it has the highest power and performance at $4 \mathrm{~m} / \mathrm{s}$ wind speed when compared with the other model, it appears from the results that the mechanical power that can be produced during each revolution is an oscillatory power, for model 2 The mechanical power starts to increase from $0^{\circ}$ and attains its maximum value at a $30^{\circ}$ rotor angle, then it drops to a minimum at a $90^{\circ}$ rotor blade angle, then again starts increasing. These outcomes lead to a conclusion that the model 2 is more efficient than model one regarding to the power and performance and that is due to its modified design which is proved by the results.

Further research will aim at developing and optimizing the wind turbine powered car under static, dynamic and fatigue conditions. Also, the parameters of Savonius wind turbine rotor will be fully analyzed to enhance its effectiveness.

\section{References}

[1] World wind energy report.: World Wind Energy Association, March (2010)

[2] I. Ushiyama, H. Nagai.: Optimum design configurations and performance of Savonius rotors, Wind Engineering, pp. 59-75 (1988)

[3] N.H. Mahmoud, A.A. El-Haroun, E. Wahbaa, and M.H. Nasef.: An experimental study on improvement of Savonius rotor performance, Alexandria Engineering Journal, Volume 51, Issue 1, pp.19-25 (2012)

[4] BhaskarJyotiChoudhury and GauravSaraf: Computational Analysis of Flow around a Two-Bladed Savonius Rotor, ISESCO JOURNAL of Science and Technology, Volume 10 Number 17, pp. 39-48 (2014)

[5] Mohammed Hadi Ali.: Experimental Comparison Study for Savonius Wind Turbine of Two \& Three Blades At Low Wind Speed, International Journal of Modern Engineering Research (IJMER), Vol. 3, Issue. 5, pp-2978-2986 (2013)

[6] KonradKacprazak, GrzegorzLiskiewicz and KrzyztofSobczak.: Numerical investigation of conventional and modified Savinous wind turbine, Renewable Energy 60, pp. 578-585 (2013)

[7] Kawamura T., Hayashi T., Miyashita K.: Application of the domain decomposition method to the flow around the Savonius rotor, 12th International Conference on Domain Decomposition Methods, T Chan, T Kako, H Kawarada and O Pironneau (Editors), (2001)

[8] Sargolzaei J.: Prediction of the power ratio and torque in wind turbine Savonius rotors using artificial neural networks, Proceedings of the WSEAS International Conference on Renewable Energy Sources, Arcachon, France (2007)

[9] H. E. Gad, A. A. Abd El-Hamid, W. A. El-Askary, and M. H. Nasef.: A New Design of Savonius Wind Turbine: Numerical
Study, CFD Letters, Vol. 6 (4) (2014)

[10] Kamoji MA,Kedare SB, Pradhu SV, Experimental Investigation on the effect of overlap ration and blade edge conditions on the performance of conventional Savonius rotor, $\mathrm{J}$ wind Eng, 32:163-78 (2008)

[11] Saha UK., Thotla S., Maity D., Optimum design Configuration of Savonius rotor through wind tunnel experiments, JWindEngIndAerodyn, 96:1359-75 (2008)

[12] KeumSooJeon, Jun IkJeong, Jar-Kyung Pan and Ki-WahnRyu, Effects of end plates with various shapes and sizes on helical Savonius wind turbines, Renewable Energy 79: 167-176 (2015)

[13] Bhaumik T., Gupta R. Performance measurement of a twobladed helical Savonius rotor, Proceedings of the 37th National \& 4th International Conference on Fluid Mechanics and Fluid Power, IIT Madras, Chennai, India. (2010)

[14] Kamoji M. A., Kedare S. B. et al., Performance tests on helical Savonius rotor, Renewable Energy, 34(3), 521-529 (2009)

[15] Eecofriend, Wing Powered Racing: DTU all set for the windy race!, 2008. http://www.ecofriend.com/wing-powered-racingdtu-all-set-for-the-windy-race.htmlAccessed 12 June 2015

[16] Ventomobile: World's first wind-powered race car!, IOP Publishing Ecofriend. http://www.ecofriend.com/ventomobileworld-s-first-wind-powered-race-car.html (2008). Accessed 12 June 2015

[17] Jeremy Jacquot, Ventomobile, World's First Wind-Powered Race Car, Ready for Primetime, IOP Publishing treehugger. $\mathrm{http} / /$ www.treehugger.com/cars/ventomobile-worlds-firstwind-powered-race-car-ready-for-primetime.html (2008). Accessed 12 June 2015

[18] Lin Edwards, Wind-powered car goes downwind faster than the wind, IOP Publishing phys.org..http://phys.org/news194851568.html (2010). Accessed 13 June 2015

[19] BBC NEWS, Wind-powered car breaks record, IOP Publishing news.bbchttp://news.bbc.co.uk/2/hi/technology/7968860.stm (2009). Accessed 14 June 2015

[20] Wind-powered car sets records in a 3,100-mile road test, IOP Publishing USA Alternative Energy NOW. http://usaalternativeenergynow.blogspot.com/2011/02/windpowered-car-sets-records-in-3100.html (2010). Accessed 12 June 2015

[21] Katie Gatto, Wind-powered car completes 3,100 mile test ride across Australia, IOP Publishing phys.org. http://phys.org/news/2011-02-wind-powered-car-mileaustralia.html (2011).Accessed 13 June 2015

[22] Mathew Sathyajith.: Basic of wind Energy Conversion from Wind Energy: Fundamentals, Resource Analysis and Economics, Springer, Berlin Heideberge New York, pp 22 (2006)

[23] Ahmad Hemami.:Wind Turbine Basic Types: Analysis and Characteristics - fromWind Turbine Technology, Unite State of America, Cengage Learning, PP.58 (2012)

[24] IEA, Key Word Energy Statistics, (2002) 
[25] GWEC, Global Wind Energy Council.: Gloable wind energy outlook (2006)

[26] Frederikus W., Andy S., Hadi A.: An experimental study on the performance of Savonius wind turbines related with the number of the blades, 2nd international conference on sustainable energy engineering and Application, ICSEEA 2014, Energy Procedia 68 297-304 (2015)

[27] Peter R.N. Childs, Bevel Gears, Mechanical Design Engineering Handbook, Elsevier Ltd, Chapter 10, PP 403 438, (2014)doi:10.1016/B978-0-08-097759-1.00010-1

[28] ArefBahramiGhahnavieh, SalehAkbarzadeh, PeimanMosaddegh,.: A numerical study on the performance of straight bevel gears operating under mixed lubrication regime, Mechanism and Machine Theory, 75: 27-40(2014)

[29] R. Keith Mobley.: Gear and Gearbox - from Plant Engineer's Handbook, Butterworth-Heinemann, pp. 636 (2001)
[30] Gitin M. Maitra.: Straight Bevel Gears - from Handbook of Gear Design, second edition, New Delhi, Tata McGraw-Hill (1989)

[31] Oliver Inderwildi and Sir David King.: Using Electric Vehicles for Road Transport, Energy - fromTransport, \& the Environment: Addressing the Sustainable Mobility paradigm, Springer, London, pp223,ISBN: 978-1-4471-2716-1

[32] Energy Losses in a Vehicle, IOP Publishing Consumer energy center.http://www.consumerenergycenter.org/transportation/co nsumer_tips/vehicle_energy_losses.html (2002). Accessed 15 June 2015

[33] Xi Zhangand Chris Mi.: Vehicle Power Management Basic concept, Vehicle Power Management: Modeling, Control and Optimization, Springer, London, pp 13 (2011)

[34] William Graebe.: Turbulent viscous flow — from Engineering Fluid Mechanics, Unite State of America, pp. 384 (2001) 